\title{
English Education Master Students' Self-Regulated Learning Strategies in Academic Writing
}

\section{Kristian Florensio Wijaya}

kristianwijaya500@gmail.com

Sanata Dharma University, Yogyakarta

\begin{abstract}
There is a propensity for language teachers to handicap graduate students as independent, competent, and strategic academic writers. Therefore, it is easier to discover graduate students struggling intensely to produce and publish qualified academic writing products to targeted journal articles. Due to this ubiquitous fact, self-regulated learning strategies need to be entrenched potently within L2 academic writers to enable them to become more mindful, resourcefulness, autonomous, and proficient academicians who excel in their subject-specific fields. This was a small-scale qualitative study implementing qualitative content analysis to obtain a more obvious portrayal regarding some specific phenomena taken place in one particular circumstance. To fulfill this objectivity, two research instruments were utilized in this study namely the Likert-scale Questionnaire and interview protocols to maintain the robustness of the data gathering processes. 15 English Education Master Students together with 3 selected interviewees were also invited to fill out the questionnaire and participate in the interview activities. In line with the gathered data, the qualitative results revealed that the majority of English Education Master Students have transformed into more lifelong and proficient academic L2 writers for they continuously showed greater resilience, efforts, commitment to accomplish various academic writing projects.
\end{abstract}

Keywords:

Self-regulated learning strategies, academic writing, qualitative content analysis, academic L2 writers

How to cite:

Wijaya, K.F. (2021). English Education Master Students' Self-Regulated Learning Strategies in Academic Writing. Journal of English teaching, 7(1), 15-29. DOI: https://doi.org/10.33541/jet.v7i1.2313 


\section{INTRODUCTION}

Becoming proficient EFL writers has been one of the indispensable skills that need to be mastered by EFL learners in this industrial revolution 4.0 era. This fact is closely intertwined with the posited writing theory proposed by Hammann (2005) who states that writing can determine EFL learners' overall learning success and achievements in the target language learning ventures. Harris et al., (2012) also assert that to enable EFL learners to be more skillful in writing, it is indispensable to prompt them to practice their academic writing skills continuously. In sharp contrast, producing a high-quality piece of academic writing has been indicated as a challenging second language learning journey since EFL learners are required to generate, manage, and incorporate their ideas into such constructive written works (see Hashemian and Heidari, 2013). More specifically, in the Indonesia EFL learning context, graduate students are commissioned to produce and publish at least one qualified academic work to one particular accredited journal as one of the requirements to graduate. This fact will even be more challenging after discerning that most graduate students encounter serious academic writing hurdles due to their lack of motivation, self-confidence, and time management in accomplishing those demanding tasks. This major academic writing issue is in concord with the findings discovered by Fujioka (2001) and Takagi (2001). They revealed that the majority of Asian EFL learners at University levels generally had a difficult time in developing their academic writing skills due to the paucity of self-regulated learning strategies in writing. As a consequence, it is easier for language teachers to find that the majority of EFL learners tend to postpone their academic writing projects, ingrain negative emotions while confronting writing, and cease the writing processes.

To overcome all of the aforementioned academic writing barriers, self-regulation should be internalized earlier at the outset of academic writing processes. Self-regulation offers a wide array of positive impacts not only for academic writing achievements but also the whole self-regulatory skills in better controlling writing processes. Further, selfregulation also enables learners to form positive habits in their writing processes, intelligently select appropriate learning strategies working best for their writing processes, be aware of their writing progresses, and have a stronger willingness to evaluate their writing achievements and progresses (see Wolters, 2011, Frizelle and Graham, 2005). The major aim of self-regulation in charge of EFL learners' academic writing processes is to direct their whole attention to heed more exhaustive focus on learning by activating, utilizing, and modifying particular cognitions along with behavioral aspects to achieve the desired learning outcomes. Ramdass and Zimmerman (2011) argue that self-regulation attempts to train learners to be cognitively, motivationally, and behaviorally stable in managing their learning rides with a hope that gratifying learning outcomes will be grasped after committing to all of these trajectories. Concerning these possible merits potentially offered by self-regulated learning strategies in academic writing, it will be worthwhile for language teachers to implement this learning strategy, particularly when learners confront serious obstacles during engaging in academic writing processes. By becoming more self-regulated learners, they will be capable of inculcating positive feelings and emotions in an attempt to generate qualified 
academic writing products. Li et al., (2018) state that proficient EFL writers are far better in managing their writing processes for they have transformed into better controllers over their writing. Through viable utilization of self-regulated learning strategies, EFL learners are also able to improve their academic writing competencies and produce highquality writings since they have been fully motivated to dedicate all of their best efforts and perseverance towards this process. Boscolo and Hidi (2006) also mention that a higher degree of volition enables learners to foster their writing skills and yield better writing products simultaneously. The most important matter to note is all of these rewarding academic writing outcomes can be grabbed fully by learners when they are willing to cope with various learning obstructions impeding their academic writing processes and view adversity as one of the precious opportunities for them to thrive and foster their writing skills. Wolters and Mueller (2010) postulate that self-regulated learners can preserve their resilience and motivation constantly amid a wide variety of impediments deteriorating their ongoing learning dynamics. By carrying out all of the above-mentioned actions, EFL learners will not merely create a higher degree of enjoyment and full ownership in their academic writing voyage but also become more life-long scholars who are always willing to maintain their intellectual curiosity both inside and outside the classroom walls.

In the same vein, there were seven prior studies conducted on the significance of self-regulated learning strategies in academic writing accompanied by some relevant additional studies closely related to self-regulatory skills in other second languagelearning areas. The first study was conducted by Farahani and Faryabi (2017) who investigated the role of self-regulated learning capacities in Iranian EFL Undergraduates' argumentative writing task performance. They discovered that introducing self-regulated learning strategies in academic writing had brought about significant impacts for further EFL learners' writing achievements since it had been considered as one of the reliable predictors towards overall writing performances. In the second relevant study, Wang et al., (2017) also found that Chinese Undergraduate EFL learners regarded the academic writing process as a captivating activity in which they potentially develop their academic literacy skills. This positive perspective was entrenched strongly since they had become more energized and highly motivated in accomplishing various academic writing tasks through self-regulatory processes. Teng and Zhang (2018) in their study regarding the impacts of self-regulated learning skills on writing performances revealed that the majority of EFL learners were able to be more proactive and critical strategies seekers over their writing processes in attempting to accomplish various assigned writing tasks successfully. Furthermore, Zumbrunn, Tadlock, and Roberts (2011) found that language teachers noted notable improvements in their learners' writing performances, motivation, and endeavor since they had been flair in overcoming various challenges come over their writing processes. Mbato (2013) in his study of self-regulatory skills in academic reading also contends that a higher level of self-regulated learning strategies leads learners to infuse more positive emotions in their learning processes. Dakhi and Damanik (2018) also discovered that motivation in reading also plays a pivotal role for EFL learners' second language reading development 
since it influences the specific assigned learning materials and learning dynamics potentially affect learners' reading competencies. Naibaho (2016) revealed that Undergraduate students at the Christian University of Indonesia had successfully improved their academic essay writing performances through consultancy writing protocol. Corresponding to the prior finding of the ultimate study, it can be assumed that EFL learners' self-regulatory skills in academic writing can be improved optimally when insistent writing assistances are always provided for them amid writing dynamics. In other words, this consultancy writing protocol can be surmised as one of the indispensable parts of self-regulated learning strategies that need to be incorporated by language teachers in academic writing contexts to enable EFL university learners to be more mindful, corrective, and autonomous in revising some possible writing errors.

To the best of the researcher's knowledge, prior seven studies relevant to selfregulated learning strategies in academic writing had successfully offered some renewable insights corresponding to the current academic writing practices with the assistance of self-regulated learning. However, there has been a paucity of research probing graduate students' self-regulated learning strategies in academic writing. Due to this fact, the researcher is currently motivated to conduct a more exhaustive study of English Education Master Students' self-regulated learning strategies in academic writing to promote some possible insights for all English language teaching experts and practitioners all around the globe, particularly in Indonesia EFL learning context regarding fruitful academic writing outcomes obtained by these graduate students after incorporating self-regulated learning strategies in their academic writing projects. In conformance to this major research objectivity, one research problem was formulated in this study namely, what were the specific learning outcomes attained by English Education Master Students after implementing self-regulated learning strategies in academic writing processes?

\section{LITERATURE REVIEW}

The researcher commenced this part by delineating two relevant learning theories tightly interwoven with the research theme namely the advantages of self-regulation in learning together with the relationship between self-regulated learning and writing. More in-depth explanations regarding those two specific theories can be discerned as follow.

\section{The Advantages of Self-Regulation in Learning}

Zimmerman (2002) advocates that self-regulation had successfully shifted the landscape of second language learning in these recent years. Concerning this view, he also added that there is a significant change in labeling meaningful learning and successful EFL learners since the majority of English language practitioners along with experts had already considered self-regulation as one of the most essential approaches that need to be stored at their disposal. In the light of self-regulated learning context, successfully language learners can be handicapped as individuals who have established robust willingness to exhort more powerful controls over the ongoing learning processes. Zimmerman and Schunk (2007) argue that to be more self-regulated, learners need to be 
able to transform into more proactive learning participants who readily shoulder the demanding responsibility of learning itself. To breed self-regulated learners who are capable of taking greater control over their learning journeys, language teachers are equally suggested to enact more supportive learning circumstances wherein learners are trained to develop their self-regulatory skills intensely (see Boekaerts, 1999). In tune, some relevant studies have exhibited advantageous learning values imparted by selfregulated learning. Zimmerman and Schunk (2001) discovered that by regulating their learning processes independently, learners will potentially able to obtain more satisfying learning outcomes. Kitsantas, Winsler, and Huie (2008) found that self-regulated learners outperform other learning companions who are less self-regulated in their learning in terms of learning progress, improvements, and achievements. Lastly, Boekaerts, Pintrich, and Zeinder (2000) also revealed that self-regulatory skills enable learners to identify their specific strengths and weaknesses aid them to move to more advanced learning dynamics. Contingent on these previous findings, it is thus well stated here that self-regulation will potentially generate more proactive, motivated, and confident learners who are desirous of being self-initiators in their learning processes.

\section{The Relationship Between Self-Regulated Learning and Writing}

Since writing has been indicated as one of the most challenging and dispiriting second language learning activities, EFL learners are commissioned to not only produce good quality writing products but also organized, contextual, understandable, and purposeful forms in the standardized written forms (see Harris et al., 2008). Graham, Gillespie, and McKeown (2013) categorize writing as a demanding cognitive task in which learners should be able to regulate the external; learning environments and internal factors; writing competencies, and knowledge of subject-specific skills to generate more qualified pieces of written information. Due to this complex nature of writing, language teachers are advised to arm learners with ample self-regulatory skills to confidently confront any kinds of challenges obstructing their writing processes. This possible suggestion was well echoed with the theory of self-regulated learning in writing proposed by Lane et al., (2006). They suggested that language teachers need to heed learners' attention to monitor, revise, and edit their writing products gradually to enable them to become more autonomous writers. Dealing with the role of self-regulated learning in writing cannot be detached from existing learners' beliefs in writing. It can also be stated that EFL learners will be able to accomplish their given writing tasks when they believe that writing is not innate, yet a learnable skill. On the contrary, when learners perceived writing skills are inborn, they prone to halt and retreat from their writing processes. This perspective is tightly interwoven with the finding of a prior study of the relationship between writing beliefs and self-regulatory behavior in writing conducted by Hammann (2005). He discovered that EFL learners' positive attitudes toward writing tasks influenced their self-regulatory behavior during the writing processes. Moreover, self-regulated learning strategies can also improve the quality of writing products since learners have been well reminded to compose their writing products more conscientiously and determine precise writing strategies intelligently suit 
best for their writing needs. This positive trajectory is in agreement with the finding of a previous study discovered by Glaser and Brunstein (2007). They found that the successful transference of self-regulated learning instructions provided better learning assistances for EFL writing learning processes and allowed them to generate high-quality writing products compared to other learning counterparts who merely received technical writing instructions. Substantiating these aforementioned findings, Fahim and Rajabi (2015) also revealed that continuous implementations of self-regulated learning strategies increased EFL learners' self-efficacy, motivation, and writing performances significantly. Ultimately, Mehrabi, Kalantarian, and Boshrabadi (2016) also shared similar findings concerning previous research results. They noted that there is a notable improvement in standardized EFL writing tests done by self-regulated learners in terms of the scores compared to those who have never been exposed to self-regulated learning strategies. In accord with these relevant studies, we should begin to rethink that instead of pressurizing EFL learners with ample technical writing conventions and terms, it is well-started for language teachers to make them become more organized individuals in their academic writing processes by starting veering their learning pathways into more self-regulated manners.

\section{METHOD}

Practically speaking, this research was conducted qualitatively to obtain clearer pictures of the observed occurrence regarding specific implementations of self-regulated learning strategies in academic writing. Creswell and Clark (2004) define qualitative study as an inquiry approach in which the researchers are obliged to analyze each obtained finding more exhaustively, create more meaningful and reliable themes based on profound reflections, and produce more in-depth reports closely interlinked with the defining themes. Furthermore, to run this qualitative study successfully, the researcher also harnessed two research instruments namely the Likert-scale Questionnaire and interview protocols. The Likert-Scale Questionnaire comprised of 10 statements concerning English Education Master Students' self-regulated learning strategies specifically applied in academic writing processes. While the interview questions consisted of 5 inquiries regarding fruitful learning outcomes experienced by English Education Master Students after implementing self-regulated learning strategies in their academic writing. To achieve this objectivity, qualitative content analysis was incorporated in this study to enable the researcher to delineate more meaningful categorizations typifying the data gathered from research participants.

Elo et al., (2014) state that the primary aim of qualitative content analysis is to portrait each research finding consistently and represent it in the forms of accurate categorizations concerning the authenticity of the obtained data to maintain trustworthiness. Regarding this definition, the researcher planned to analyze, categorize, and interpret the data garnered from the research participants more conscientiously to reduce some possible misconceptions regarding the personal interpretative data analysis carried out by the researcher. With the sincere help of 15 English Education Master Students batch 2019, the researcher felt certain that he would be able to operate this 
research method efficiently and the intended meanings of each theme could be imparted successfully for the readers. Thus, 15 above-mentioned participants were invited to fill out The Likert-scale Questionnaire concerning self-regulated learning strategies they implemented in academic writing. This questionnaire would be administered in an online form with the assistance of Google Forms to enable the research participants to give appropriate responses toward some imparted statements. After completing the first data gathering process, the researcher also asked three interviewees to participate in the interview sections to attain more in-depth elucidation corresponding to tangible learning outcomes they had grasped after internalizing self-regulated learning strategies in academic writing processes. More specifically, the researcher would present and decipher the qualitative findings argumentatively with the aid of a simple bar chart to preserve the robustness out of the gathered data. In conformance to this strategy, it is also of critical importance to note here that some relevant findings, theories, and excerpts of the interview protocols would also be integrated with prior data formulations to make each qualitative finding become more positively cemented with each other, which potentially produce more reliable research results.

\section{FINDINGS AND DISCUSSION}

This part is aimed to give an intended response towards the major research problems enacted in this study namely what were the specific learning outcomes attained by English Education Master Students after implementing self-regulated learning strategies in academic writing processes? The findings will be complemented by some appropriate theories and current research discoveries relevant to the major theme of this study. More specifically, two emerging themes emanated from this study namely: (a) English Education Master Students transformed into life-long learners, and (b) English Education Master Students became more proficient academic L2 Writers.

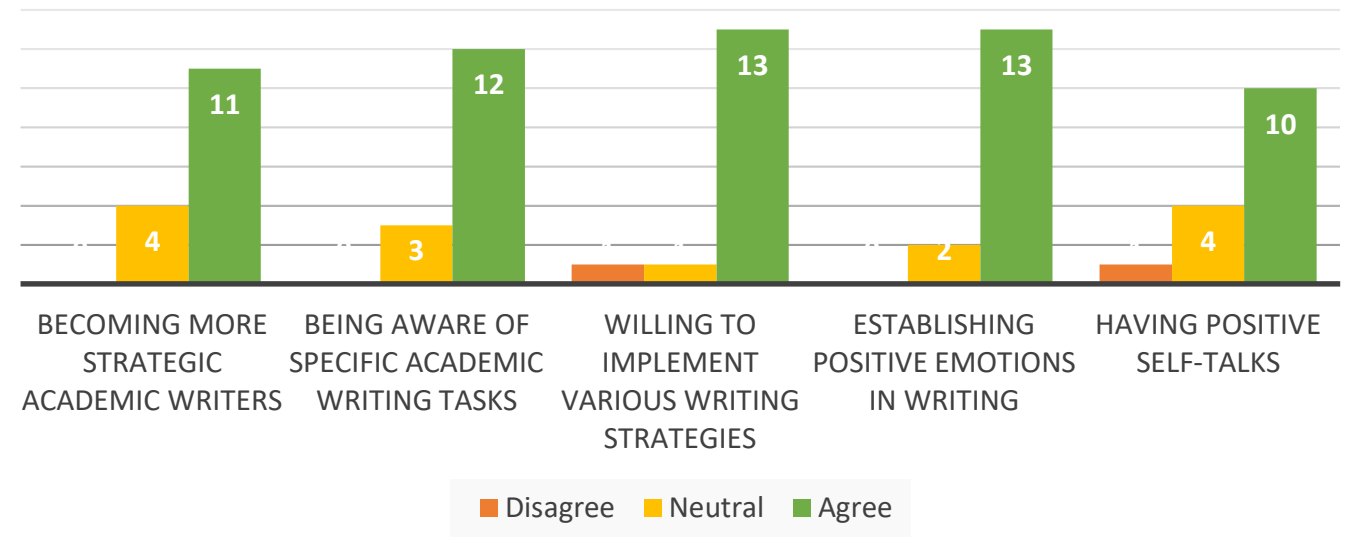

Figure 1. English Education Master Students Transformed into Life-Long Learners (79\% Participants Agree)

As can be discerned above, this first figure attempted to decipher 5 specific strategies English Education Master Students have incorporated in academic writing 
processes to be more life-long learners. In the light of self-regulated learning strategies, life-long learners can be defined as academicians who are always striving to construct a wide array of knowledge independently and collaboratively with others to create a more widespread deployment of targeted competencies. Aligning with this conception, it is interesting to observe here that the two highest consecutive agreements arose from the third and fourth finding in which English Education Master students have considered that implementing a wide array of strategies and inculcating more positive emotions can determine the successful accomplishment of their academic writing projects. Regarding the deliberate use of various writing strategies, L2 writers will not merely be able to discover a higher degree of enthusiasm in an attempt to finish demanding academic writing projects but also become cognitively, behaviorally, and motivationally motivated to embrace any kinds of possible strategies corresponding with their writing tasks. As a result, these types of L2 writers will experience higher success in academic writing compared to those counterparts who solely rely on their intuitions or personal preferences amid writing activities. This elucidation is closely interlinked with the theory of writing strategies proposed by Zimmerman and Schunk (2011). They mentioned that successful implementations of writing strategies will allow L2 writers to exert more powerful controls over their writing processes to fulfill their targeted writing goals set before. In their study of the particular relationship between self-regulated learning strategies and academic writing, Fahim and Rajabi (2015) also discovered that introducing EFL learners to a wide variety of writing strategies assist them to be more proficient and autonomous L2 writers and lead them closer to gratifying writing achievements. Concerning this finding, we should not overlook the importance of molding positive emotions at the commencement of academic writing activities since these rewarding elements will allow L2 writers to continue regulating the whole writing process more efficiently despite various impediments hindering their writing journeys. This finding is in agreement with the theory of self-regulated learning proposed by Mbato (2013). He believed that positive emotions infused by EFL learners will enable them to regulate their target language learning processes in a better avenue. Teng and Zhang (2016) also argue that through positive emotions, L2 writers will be more capable of planning, monitoring, and evaluating their writing products more effectively.

Furthermore, the third-highest category goes to the second finding discovered in this first theme clearly stated that English Education Master students have gained a higher degree of awareness in confronting given academic writing tasks. This particular awareness is of utmost importance to allow L2 writers to select and implement precise strategies best suit their writing objectives. Along the same line, when these L2 writers have fully utilized appropriate writing strategies, it is worth noting here that they will be able not only to accomplish designated various academic writing tasks but also foster the overall quality of their writing products and make them more persistent in enduring longlengthy dynamics of writing. A similar finding was also discovered in a prior study of self-regulated learning strategies in academic writing conducted by Brunstein and Glaser (2011). They found that effective utilization of particular writing strategies had enhanced L2 learners' interests and qualities of their writings. Dornyei and Ryan (2015) also assert 
that by becoming more critical strategy selectors, L2 writers can improve their writing competencies and reach the desirable writing outcomes successfully. Moreover, the third-highest category emanated from the first finding, which reiterates the critical importance for English Education Master Students to continuously be more strategic academic writers. Again, strategic academic L2 writers are required to harness various probable strategies enabling them to achieve the desired outcomes upon the successful accomplishments of their specific tasks. Thus, language teachers should accentuate more intensely on helping L2 writers to judiciously and flexibly determine precise writing strategies corresponding to their ongoing academic writing tasks to preserve their higher degree of motivation to produce more qualified pieces of writing. This finding is closely correlated with the theory of learning strategies propounded by Zimmerman and Schunk (2011). They believed that all proactive and mutual activation of selected learning strategies will promote significant impacts on EFL learners' further learning development. Another merit of harnessing precise learning strategies is also proffered by Zhang, Thomas, and Qin (2019) who believed that strategic learners transformed into more autonomous, life-long, and proficient academicians since they have been flair in internalizing any kinds of learning strategies aligning with their specific target language tasks. All of the above-mentioned explications and relevant theories have also shared a tight-knit relationship with the excerpts taken from the three interviewees as follow:

[ One of my strategies in doing academic writing is to monitor my writing processes by giving comments and criticisms to my own writings in order to make me become more independent writers]

[I usually make use of understandable sentences and expressions in my academic writing tasks in order to enable all readers to understand my thoughts in writing. Further, I also delete some unnecessary words in my writing to avoid any kinds of misunderstandings]

[I make sure to read my previous writing projects for relevant sources. In addition, I plan what sections to write ahead of time, but I don't get stressed out when I cannot fulfill my plans or goals]

While the lowest finding discovered in this first theme denotes another pivotal aspect of having positive self-talks before commencing academic writing tasks. By having positive self-talk at the beginning of academic writing processes, English Education Master Students will be more strongly motivated and committed to accomplishing given writing tasks amid unpredictable obstructions, difficulties, and challenges. This positive learning action was taken place since these learners have instilled more robust internal motivation within themselves and not expend unnecessary attention to other disruptive occurrences potentially hindering their writing journeys. This last finding is tightly interwoven with the theory of positive self-talks postulated by Lee (2017). He states that self-regulated learners who undergird more positive self-talks will potentially become more successful, autonomous, and competent knowledge 
seekers. More importantly, delving about the pivotal role of forming positive emotions through positive self-talk, in this case, cannot be detached from self-efficacy theory. Since self-efficacy only takes a smaller part, yet significant influence in this study, the researcher only provides a concise overview regarding the importance of this element in breeding self-regulated academic writers by borrowing from the theory of self-efficacy enacted by Yanar and Bumen (2012). They argued that higher self-efficacious learners are committed to reaching their desirables learning goals by ignoring various negative emotions and magnifying more positive emotions at once. Following excerpts of interviews concerning the ultimate finding can be seen as follow:

[I always keep saying to myself that although academic writing processes are very difficult and not make me feel comfortable, but the work of it will be beneficial for my future career]

[What makes me always think academic writing as a positive activity is I remember the goals of my writing. For example, I need my writing to be published in a good journal. This goal motivates me a lot to create good writing so that I will successfully publish it]

[I always tell myself that I am more than able to be a more proficient academic writer and convince myself that my hard works and efforts will not betray me. I also keep saying that my academic writing tasks can be finished successfully when I better regulate my emotions and feelings toward this kind of painstaking activity]

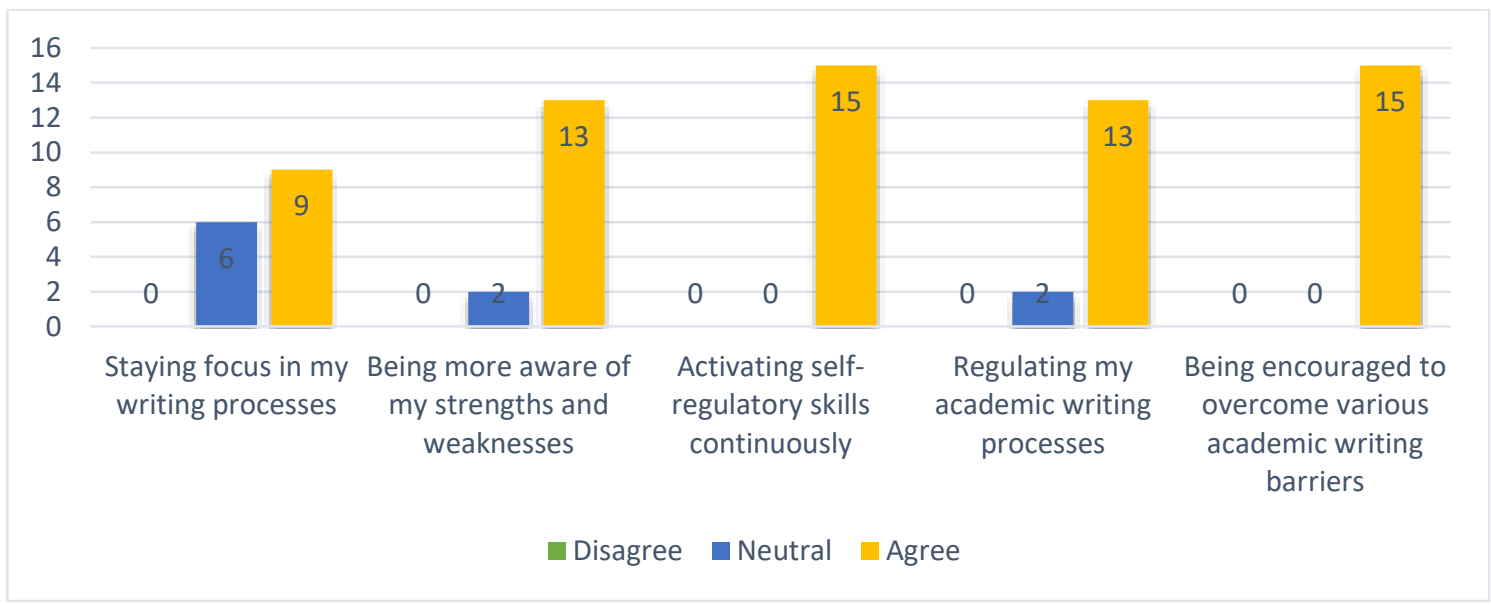

Figure 2. English Education Master Students Become More Proficient Academic L2 Writers (87\% Participants Agree)

From this second theme, it can be surmised that the majority of English Education Master Students have become more proficient academic L2 writers. This postulation is corroborated with two consecutive highest categories emanated from the third and fifth findings where they all agreed to activate self-regulatory skills continuously in academic writing processes and overcome various writing barriers. As previously mentioned, to be proficient academic L2 writers, second language learners have to harness self- 
regulatory skills continually to transform them into more autonomous, resilient, and competent scholars who are not extremely dependent on their language teachers for transferring necessary information or honing their academic skills through one trajectory; one-way teaching instruction. These types of indulgent learners will not be able to critically select appropriate learning strategies best suit their learning needs since they have been accustomed to waiting passively for their teachers to impart the intended competencies. As a result, they will experience learned helplessness when encountering a wide variety of challenges, obstacles, and difficulties in their learning voyage. This learning interference not merely disrupts the whole learning dynamics but also brings disastrous effects on learners' mental. In conformance with academic writing contexts, it is, hence, easier to discover L2 writers who cease doing their writing projects, not skillful enough in mastering writing tasks and handicap their writing failures as the inability to produce high-quality writing products. All of these findings and arguments echoed well with the theory of self-regulatory skills together with learning persistence proposed by Sholeh (2019) and Finney et al., (2018). The first researcher mentions that learners possessing lower self-regulatory skills tend to plunge themselves into ineffective learning experiences and heavily dependent on their teachers eventually directing them to learning failures. Linked to this theory, the latter researcher also propounded that highly self-regulated learners confidently and bravely dealing with many kinds of learning hurdles hampering their learning processes since they have been proactive knowledge constructors, adaptable persons, and persistent fighters.

In the light of the two aforementioned findings, it is also worthwhile to point out here that the spirit of self-regulated learning through academic writing lenses can be born when second language learners have successfully identified their specific strengths and weaknesses contributing to their learning success. This successful identification will allow L2 writers to keep their right track on painstaking writing processes since they are willing to endure every challenging step heading them to achieve greater learning success after accomplishing this demanding learning trajectory. To restate, this nature of self-regulated learning is made in conjunction with self-efficacy since self-regulated learners possessing a higher level of self-efficacy prone to exhibit more long-lasting persistence, endeavor, and commitment to foster their targeted language learning competencies and achieve determined learning outcomes fully. This finding is akin to the theory of self-regulated writers and academic writing processes yielded by Zimmerman and Schunk (2011) and Oxford (2016). The first-mentioned researcher believed that self-regulated writers automatically infused a higher level of self-efficacy since they are familiar with their strengths along with weaknesses, exhort insistent efforts to reach their intended learning outcomes, and improve their learning competencies continually. The second researcher also argued in the same way as the first researcher since he also stated that self-regulated learners consistently display those characteristics namely becoming more high-quality knowledge constructors, committed academicians, and prudent information seekers. Further, three additional excerpts taken from the interviewees will also be displayed as follow to corroborate the findings and theories of this current study:

[I consistently revise my writings before submitting them to journal articles or compare my writings to other examples taken from those journals in order to match the requirements demanded by those journals] 
[I usually share my writing problems with my friends and ask for some beneficial advice from them. I also recheck my writings continuously. The last thing that I always do is to strictly stick to my schedule to finish my writing projects timely]

[Usually, I create the first draft or mind maps about the contents of my writings. I divide them into some paragraphs and write down the important points I want to later discuss in my writings]

The more complex matter should also be taken into our disposal while defining the real-essential value of self-regulated learning strategies since the lowest category stemmed from the first category in this theme alluded that not all English Education Master Students have maintained their long-term focus in doing various academic writing tasks. Heeding profound attention on academic writing tasks refers to L2 writers' capacities to regulate their cognition, motivation, behaviors, and learning circumstances sustaining the overall learning processes. By doing so, L2 writers will not be distracted easily with various learning disruptions impeding their ongoing learning dynamics since they constantly expend all their energy, efforts, and time to accomplish given learning tasks and foster their competencies through this long-lengthy process. This ultimate finding is closely related to the grounded theory of self-regulated learning strategies imparted by Andrade and Evans (2012). They argued that self-regulated learners commonly possess capabilities of regulating their thoughts, feelings, emotions, cognition, motivation, behavior, and designated learning surroundings more stably. In correspond to this theory, the excerpts garnered from the three interviewees also shared similar perspectives regarding the successful utilization of self-regulated learning strategies in academic writing. That evidence can be seen as follow:

[My common impediment in academic writing are using appropriate grammar and academic expressions. To overcome these problems, I usually learn a lot from other published studies in some journal articles in order to produce better writings]

[The best thing I do so far is by asking my friends to proof-read my writing. I think the more I write, the better my writing is. I can see that I develop my writing skills because I write more and more. For example, in deciding the dictions. Today, I feel the dictions I use is better and more suitable rather than my previous writing a long time ago. So the answer is always keep practicing]

[I don't want to put too much stressful feelings and burdens in my writing. Therefore, I always try to write when I am in such a good mood. When it does not go in that way, I will stop and relax myself first]

\section{CONCLUSION}

Taken together, it can be stated here that the majority of English Education Master students taking part in this study have successfully transformed into more proficient and life-long L2 academic writers who are experts in their subject-specific areas. From this positive occurrence, we can discern an important interplay between self-regulated learning strategies in academic writing processes. It has been evinced that through a wide array of complexities and painstaking processes discovered in academic writing processes, these L2 academic writers have fully become the main controllers, self- 
initiators, and self-starters in dealing with many kinds of emerging distractions, hurdles, challenges, and adversity. Put differently, their long-lasting efforts, persistence, and robust writing endeavor have brought them to experience greater academic writing successes beneficial for their future careers. This success, partially, should be confessed that it is due to the insistent incorporation of self-regulated learning strategies internalized by their academic writing advisors. As a result, their internal and external motivations work as a mutual complement with each other leading them to be more autonomous, resilient, and desirous L2 academic writers.

This current study has revealed a new horizon to the expanding bodies of studies that explore the importance of self-regulated learning strategies in academic writing processes, particularly for the dearth of those studies investigating the crucial role of this learning theory for English Education Master students. Despite the gratifying research results and breakthrough which is made, two limitations of this present study should be sincerely confessed accompanied by further recommendations for future studies. The first drawback in this study is since the researcher conducted this study after the invited participants being exposed to self-regulated learning skills in such a long-term recession of time hiatus, the results of this study are still debatable by asking whether those participants still implemented these learning skills outside of academic writing classroom walls. Further shortage of this study is due to the limited number of participants who took part in this study since we are all in a pandemic situation and not all classes are willingly available to be other resourceful research sites for this current study. Thus, future researchers are highly recommended to invite a higher number of research participants engaging in academic writing classes to produce more significant research results.

\section{REFERENCES}

Andrade, M. S., \& Evans, N. W. (2012). Principles and practices for response in second language writing: Developing self-regulated learners. Routledge.

Boekaerts, M. (1999). Self-regulated learning: Where we are today. International journal of educational research, 31(6), 445-457.

Boekaerts, M., Pintrich, P. R., \& Zeidner, M. (2000). Self-regulation: An introductory overview. In Handbook of self-regulation (pp. 1-9). Academic Press.

Boscolo, P., \& Hidi, S. (2006). The multiple meanings of motivation to write. In Writing and motivation (pp. 1-14). Brill.

Brunstein, J. C., \& Glaser, C. (2011). Testing a path-analytic mediation model of how self-regulated writing strategies improve fourth graders' composition skills: A randomized controlled trial. Journal of educational psychology, 103(4), 922.

Creswell, J. W., \& Clark, V. L. P. (2004). Principles of qualitative research: Designing a qualitative study. Office of Qualitative \& Mixed Methods Research, University of Nebraska, Lincoln.

Dornyei, Z., \& Ryan, S. (2015). The psychology of the language learner revisited. Routledge.

Elo, S., Kääriäinen, M., Kanste, O., Pölkki, T., Utriainen, K., \& Kyngäs, H. (2014). Qualitative content analysis: A focus on trustworthiness. SAGE open, 4(1), 1-10.

Fahim, M., \& Rajabi, S. (2015). Applying self-regulated strategy development model of instruction to teach writing skill: Effects on writing performance and writing motivation of EFL learners. International journal of research studies in education, 4(2), 29-42.

Wijaya: English Education Master Students' Self-Regulated Learning Strategies in Academic Writing 
Finney, S. J., Barry, C. L., Horst, S. J., \& Johnston, M. M. (2018). Exploring profiles of academic help seeking: A mixture modeling approach. Learning and individual Differences, 61, 158-171.

Frizzelle, R., \& Graham, S. (2005). Self-monitoring of attention versus self-monitoring of academic performance: Effects among students with ADHD in the general education classroom. The Journal of Special Education, 39(3), 145-157.

Fujioka, M. (2001). Asian students' English writing experience. The Language Teacher, 25(11).

Glaser, C., \& Brunstein, J. C. (2007). Improving fourth-grade students' composition skills: Effects of strategy instruction and self-regulation procedures. Journal of educational psychology, 99(2), 297.

Graham, S., Gillespie, A., \& McKeown, D. (2013). Writing: Importance, development, and instruction. Reading and writing, 26(1), 1-15.

Hammann, L. (2005). Self-regulation in academic writing tasks. International journal of teaching and learning in higher education, 17(1), 15-26.

Harris, K. R., Lane, K. L., Graham, S., Driscoll, S. A., Sandmel, K., Brindle, M., \& Schatschneider, C. (2012). Practice-based professional development for selfregulated strategies development in writing: A randomized controlled study. Journal of Teacher Education, 63(2), 103-119.

Hashemian, M., \& Heidari, A. (2013). The relationship between L2 learners' motivation/attitude and success in L2 writing. Procedia-Social and Behavioral Sciences, 70, 476-489.

Khomeijani Farahani, A. A., \& Faryabi, F. (2017). The role of self-regulated learning capacities in Iranian EFL undergraduates' argumentative writing task performance. Research in English Language Pedagogy, 5(2), 203-222.

Kitsantas, A., Winsler, A., \& Huie, F. (2008). Self-regulation and ability predictors of academic success during college: A predictive validity study. Journal of advanced academics, 20(1), 42-68.

Lane, K. L., Graham, S., Harris, K. R., \& Weisenbach, J. L. (2006). Teaching writing strategies to young students struggling with writing and at risk for behavioral disorders: Self-regulated strategy development. Teaching Exceptional Children, 39(1), 60-64.

Lee, I. (2017). Classroom writing assessment and feedback in L2 school contexts. Singapore: Springer Singapore.

Li, M., Zheng, C., Liang, J. C., Zhang, Y., \& Tsai, C. C. (2018). Conceptions, selfregulation, and strategies of learning science among Chinese high school students. International Journal of Science and Mathematics Education, 16(1), 6987.

Mbato, C. L. (2013). Facilitating EFL learners' self-regulation in reading: implementing a metacognitive approach in an Indonesian higher education context.

Meehan, K. B., Ueng-McHale, J. Y., Reynoso, J. S., Harris, B. H., Wolfson, V. M., Gomes, H., \& Tuber, S. B. (2008). Self-regulation and internal resources in schoolaged children with ADHD symptomatology: An investigation using the Rorschach inkblot method. Bulletin of the Menninger Clinic, 72(4), 259-282.

Mehrabi, M., Kalantarian, S. R., \& Boshrabadi, A. M. (2016). The interplay between self-regulation strategies, academic writing achievement and gender in an Iranian L2 context. Journal of Applied Linguistics and Language Research, 3(2), 230-239.

Wijaya: English Education Master Students' Self-Regulated Learning Strategies in Academic Writing

DOl: https://doi.org/10.33541/jet.v7i1.2313 
Naibaho, L. (2016). Improving Students' Essay Writing Ability through Consultancy Prewriting Protocol at Christian University of Indonesia. The Asian EFL Journal, 3, 147-160.

Oxford, R. L. (2016). Teaching and researching language learning strategies: Selfregulation in context. Taylor \& Francis.

Ramdass, D., \& Zimmerman, B. J. (2011). Developing self-regulation skills: The important role of homework. Journal of advanced academics, 22(2), 194-218.

Schunk, D. H., \& Zimmerman, B. J. (2007). Influencing children's self-efficacy and selfregulation of reading and writing through modeling. Reading \& writing quarterly, 23(1), 7-25.

Sholeh, A. (2019). Self-Regulated Learners in Voluntary Reading: The effects and Implications on EFL Reading Classes. Journal for the Education of Gifted Young Scientists, 7, 867-883.

Takagi, A. (2001). The need for change in English writing instruction in Japan. Language Teacher Kyoto JALT, 25(7), 5-10.

Teng, L. S., \& Zhang, L. J. (2016). A questionnaire-based validation of multidimensional models of self-regulated learning strategies. The Modern Language Journal, 100(3), 674-701.

Teng, L. S., \& Zhang, L. J. (2018). Effects of motivational regulation strategies on writing performance: A mediation model of self-regulated learning of writing in English as a second/foreign language. Metacognition and Learning, 13(2), 213240.

Wang, H. H., Chen, H. T., Lin, H. S., \& Hong, Z. R. (2017). The effects of college students' positive thinking, learning motivation and self-regulation through a selfreflection intervention in Taiwan. Higher Education Research \& Development, 36(1), 201-216.

Wolters, C. A. (2011). Assessing strategies for the self-regulation of motivation. Handbook of self-regulation of learning and performance, 298-312.

Wolters, C. A., \& Mueller, S. A. (2010). Motivation regulation. 631-635.

Yanar, B. H., \& Bümen, N. T. (2012). Developing a self-efficacy scale for English. Journal of Kastamonu Education, 20(1), 97-110.

Zhang, L. J., Thomas, N., \& Qin, T. L. (2019). Language learning strategy research in system: looking back and looking forward. System, 84, 87-92.

Zimmerman, B. J. (2002). Becoming a self-regulated learner: An overview. Theory into practice, 4l(2), 64-70.

Zimmerman, B. J., \& Schunk, D. H. (2001). Reflections on theories of self-regulated learning and academic achievement. Self-regulated learning and academic achievement: Theoretical perspectives, 2, 289-307.

Zimmerman, B. J., \& Schunk, D. H. (2011). Self-regulated learning and performance. Handbook of self-regulation of learning and performance, 1-12.

Zimmerman, B. J., \& Schunk, D. H. (2011). Handbook of self-regulation of learning and performance. Routledge/Taylor \& Francis Group.

Zumbrunn, S., Tadlock, J., \& Roberts, E. D. (2011). Encourage Self-Regulated Learning in the Classroom. MERC Publications, 1-19. 